\title{
УДК 69.003:338.5
}

\author{
Г.А. Пурс \\ канд. екон. наук, директор \\ ORCID: 0000-0001-9647-6617
}

Н.М. Михалькевич,

начальник управления ${ }^{1}$, соискатель кафедры экономики, организация строительства и управление недвижимостью ${ }^{2}$

ORCID: 0000-0003-0202-1916

${ }^{1}$ Республиканское унитарное предприятие «Республиканский научнотехнический центр по ценообразованию в строительстве», (г. Минск, Беларусь)

${ }^{2}$ Белорусский национальный технический університет, (г. Минск, Беларусь)

\section{РАЗРАБОТКА МЕТОДОЛОГИЧЕСКИХ И ОРГАНИЗАЦИОННЫХ ПОДХОДОМ ПО ОПРЕДЕЛЕНИЮ СТОИМОСТИ СТРОИТЕЛЬСТВА ПОСРЕДСТВОМ ИСПОЛЬЗОВАНИЯ ВАРИАНТНОГО ПРОЕКТИРОВАНИЯ}

Важнейшим шагом в реализации многоступенчатой модернизации системь ценообразования в строительном комплексе стала разработка методологических и организачионных подходов по определению стоимости строительства посредством использования вариантного проектирования, которій позволяет заказчику увидеть все возможные способь строительства здания или сооружения, определить наиболее выгодные варианты экономии и способь уменьшения трудозатрат.

Статья посвящена изучению причин необходимости совершенствования системь иченообразования строительной отрасли и внедрения аналогового метода определения стоимости строительства на стадии обоснования инвестиций и разработки архитектурного проекта, исследования базь нормативно-правовых документов, направленной на реализацию аналогового метода формирования сметной стоимости строительства. Также в статье рассмотрень перспективные направления применения объектов-аналогов и направления дальнейшего развития объектов-аналогов в качестве инструмента для расчета стоимости строительства на базе технологии информационного моделирования зданий.

Экономический эффект от применения объектов-аналогов для определения стоимости строительства на прединвестиционной стадии достигается за счет снижения продолжстельности формирования сметной документации, повышения достоверности расчетов сметной стоимости в текущих ценах при обосновании инвестиций и разработке архитектурного проекта, а также за счет создания информаџионной основы для внедрения вариантного проектирования. Банк данных объектов-аналогов дает возможность быстрой и адекватной оценки необходимого объема инвестиций с проработкой нескольких альтернативных конструктивных и объемно-планировочных решений.

Предлагаемая $\kappa$ разработке автоматизированная информачионноаналитическая система позволит вести расчеты стоимости строительства на 
основании информационной базы республиканского банка данных объектов аналогов. Данный расчет охватывает все затраты, которые должен понести заказчик, чтобы получить объект, готовый к эксплуатации. Кроме того, уровень точности полученных данных позволит сориентировать заказчика касательно объема предполагаемых к освоению инвестиций в рамках планирования своей хозяйственной деятельности на долгосрочную перспективу.

Ключевье слова: стоимость строительства, сметная стоимость, вариантное проектирование, Беларусь.

Введение. С принятием Указа Президента Республики Беларусь от 11 августа 2011 года № 361 «О совершенствовании порядка определения стоимости строительства объектов и внесении изменений в некоторые указы Президента Республики Беларусь» с 1 января 2012 года в Республике Беларусь ведется активная работа по модернизации системы ценообразования в строительстве.

Главными причинами, которые привели к необходимости совершенствования системы ценообразования строительной отрасли, стали:

- наличие существенной разницы размеров средств на строительство, определяемых на предынвестиционном и инвестиционном (проектном) этапах создания строительной продукции, и размером средств, фактически израсходованных на строительство по завершении инвестиционного (строительного) этапа ее создания;

- значительные погрешности постоянного характера в определении затрат на строительство при осуществлении архитектурной деятельности, в том числе при выполнении оценки предполагаемых затрат на промежуточных этапах проектирования;

- негативное влияние постоянных корректировок проектной документации при осуществлении строительства;

- необходимость перехода строительного комплекса на строительство по неизменным договорным (контрактным) ценам.[1]

Важнейшим шагом в реализации многоступенчатой модернизации системы ценообразования в строительном комплексе стало внедрение положений нормативных документов, обеспечивающих создание методологического, организационно-правового и технического обеспечения, для решения задачи внедрения неизменных договорных (контрактных) цен, основанных на методах бюджетирования, вариантном проектировании и системе планирования затрат с использованием укрупненных показателей стоимости, расхода ресурсов и технико-экономических показателей объектов-аналогов, создаваемой республиканской базы проектной документации на типовые, повторно применяемые и индивидуальные проекты [2].

Основная часть Со вступлением в силу Указа Президента Республики Беларусь от 14 января 2014 года №26 «О мерах по совершенствованию строительной деятельности» началась работа по созданию банка данных объектованалогов и внедрению вариантного проектирования, основанного на методах экономической оценки проектных решений путем системного выбора оптимальных вариантов с учетом взаимосвязи технических и технологических 
параметров объекта со стоимостью объекта, сформированной в эталонных единицах показателей групп затрат в целях повышения достоверности оценки затрат в строительстве и решения главной проблемы инвестиционной деятельности, состоящей в том, что цена строительной продукции должна быть экономически обоснована и стабильна.

Для отлаженной работы всех участников инвестиционного цикла при эффективном функционировании банка данных объектов-аналогов потребовалась подготовка правого поля с целью решения проблем организационного, методического и аналитического характера.

Во-первых, была разработана и введена в действие постановлением Министерства архитектуры и строительства от 26 марта 2014 года №14 Инструкция о порядке создания и ведения республиканского фонда проектной документации и республиканского банка данных объектов аналогов на строительство объектов, предоставления в пользование и использования материалов и данных указанных фонда и банка данных (далее - Инструкция №14), которая определила механизм создания и порядок ведения фонда проектной документации и банка данных объектов-аналогов на основе проектно-сметной документации на строительство объектов, разработанной полностью или частично за счет средств республиканского и (или) местного бюджетов, в том числе государственных целевых внебюджетных фондов, внешних государственных займов и внешних займов, привлеченных под гарантии Правительства Республики Беларусь, кредитов банков под гарантии Правительства Республики Беларусь и областных, Минского городского исполнительных комитетов (далее - бюджетных и приравненным к ним средств). Данной Инструкцией №14 был также определен порядок предоставления в пользование и использования материалов и данных, содержащихся в фонде проектной документации и банке данных объектованалогов.

Пунктом 5 Инструкции №14 определено, что банк данных объектов-аналогов формируется также на основании информации о стоимости завершенных строительством объектов, что позволит скорректировать стоимость в зависимости от фактических затрат, понесенных заказчиком на строительство объекта [3]. Таким образом, с целью организации работы по мониторингу данных о стоимости объектов, завершаемых строительством, была утверждена приказом Министерства архитектуры и строительства от 27 ноября 2014 года №328 «О формах ведомственной отчетности на 2015 год» Анкета об объекте, завершенном строительством - Форма ведомственной отчетности (4-озс), которая представляется организациями, осуществляющими инвестиционную деятельность по вложению инвестиций в основной капитал по объектам, финансируемым за счет бюджетных и приравненным к ним средств. В последующие годы анкета переутверждалась и преобразовалась в 1-озс.

Анкета заполняется заказчиком на основании данных первичных учетных документов и технических нормативных правовых актов в области архитектуры и строительства. В Анкете указывается проектная мощность объекта строительства (площадь либо иной параметрический показатель), нормативная продолжительность строительства, фактическая дата начала и окончания 
строительства и отражается стоимость строительства по фактическим данным первичных учетных документов.

Поступившая информации о фактической стоимости завершенных строительством объектов актуализирует стоимостные показатели объекта-аналога, определенные на основании проектной документации, и позволяет создать блок информационных данных, учитывающих реальную стоимость объекта.

Еще одним важным аспектом сложного многоступенчатого процесса модернизации системы ценообразования стал тот факт, что в целях экономической оценки проектируемых объектов новые методы и системы проектирования должны быть увязаны с методами экономической оценки проектируемых объектов по критериям оптимизации стоимости, материалоемкости, продолжительности строительства, будущих эксплуатационных затрат. В связи с этим требовалось, чтобы правила подсчета объемов, характеризующих как объект в целом, так и его конструктивные и инженерные составляющие, были увязаны с эталонными единицами стоимостных затрат. Для решения поставленной задачи ГП «РНТЦ по ценообразованию в строительстве» совместно с РУП «Главгосстройэкспертиза» был разработан и утвержден приказом Министерства архитектуры и строительства от 23 февраля 2015 года №52 Технический кодекс установившейся практики «Строительство. Технико-экономические показатели объекта строительств. Правила определения площадей и объемов зданий и сооружений» (ТКП 45-1.02-302-2015 (33020)) (далее - ТКП).

Внедрение единого формата описания параметрических характеристик (натуральных показателей) для проектного обеспечения объекта инвестиционной деятельности в строительство (систематизация) на основе единых для всех участников инвестиционной деятельности в строительство нормативов и унифицированных идентификационных признаков, предусмотренных данным ТКП, обеспечивает сопоставимость и точность описаний характеристик объекта (натуральных показателей) в учетных системах участников инвестиционной деятельности в строительстве, архитектурной и строительной деятельности, позволяет унифицировать эти описания с учетом международной практики. Данный ТКП создает основу для внедрения в Республике Беларусь систем бюджетирования в инвестиционной и архитектурно-строительной сфере на всех этапах жизненного цикла строительной продукции, позволяет участникам архитектурной и строительной деятельности использовать системы планирования затрат в строительство со степенью достоверности, удовлетворяющей возможностям использования систем бюджетирования в инвестиционностроительной сфере на всех этапах жизненного цикла строительной продукции, а также создает условия для упрощения и активизации процессов продвижения продукции в сфере архитектурных услуг отечественных производителей как на внутреннем, так и на внешнем рынке.

Показатели площадей и объемов зданий и сооружений, правила определения которых установлены данным ТКП, предназначены для систематизации информации, при формировании республиканского банка данных объектованалогов, а также с целью сравнительного анализа эффективности принимаемых 
проектных решений, в том числе по сравнению с аналогичными зарубежными объектами строительства.

Следующим нормативным документом, необходимым для реализации задачи по созданию республиканского банка данных объектов-аналогов, стали Методические рекомендации по формированию технико-экономических, в том числе стоимостных и ресурсных показателей объектов строительства с целью их применения в качестве показателей объектов-аналогов, использования при планировании затрат и определении стоимости строительства, утвержденные постановлением Министерства архитектуры и строительства от 10 июля 2015 №21 и разработанные для применения на всех этапах планирования затрат, при определении сметной стоимости строительства на инвестиционной стадии строительства, формировании республиканского банка данных объектов-аналогов, систематизации информации с целью сравнительного анализа принимаемых проектных решений.

Данные Методические рекомендации определяют порядок формирования стоимостных и ресурсных показателей по предпроектной (предынвестиционной) документации и при разработке и реализации инвестиционного проекта в строительство, порядок формирования технико-экономических показателей объектов-аналогов на строительство объектов, а также порядок применения стоимостных и ресурсных показателей объектов-аналогов при определении стоимости строительства.

Комплекс нормативных правовых актов по организации порядка создания и ведения в Республике Беларусь республиканского банка данных объектованалогов на строительство объектов обеспечил возможность внедрения в практику ценообразования в строительстве методов, основанных на укрупненных показателях стоимости и стоимости объектов-аналогов. Схема поступления информации и формирования республиканского банка объектов-аналогов представлена на рис. 1 .

Республиканский банк данных объектов-аналогов формируется на основании республиканского фонда проектной документации, содержащего типовые проекты, проекты, рекомендованные для повторного применения, а также индивидуальные проекты. Республиканский банк данных объектов-аналогов представляет собой организационно-техническую систему, которая включает базу данных с информацией об отдельных показателях (в том числе стоимостных) и характеристиках объектов-аналогов (технико-экономические показатели), представленных в соответствии с проектной документацией на строительство объектов, находящихся в фонде проектной документации, а также о стоимости завершенных строительством объектов.

Процесс формирования происходит расчетно-аналитическими методами обработки технико-экономических показателей по группам затрат в разрезе проектно-технологических модулей, характеризующих виды работ и затрат, возникающих при создании строительной продукции.

Структура наполнения республиканского банка данных объектов-аналогов представлена на рис. 2. 


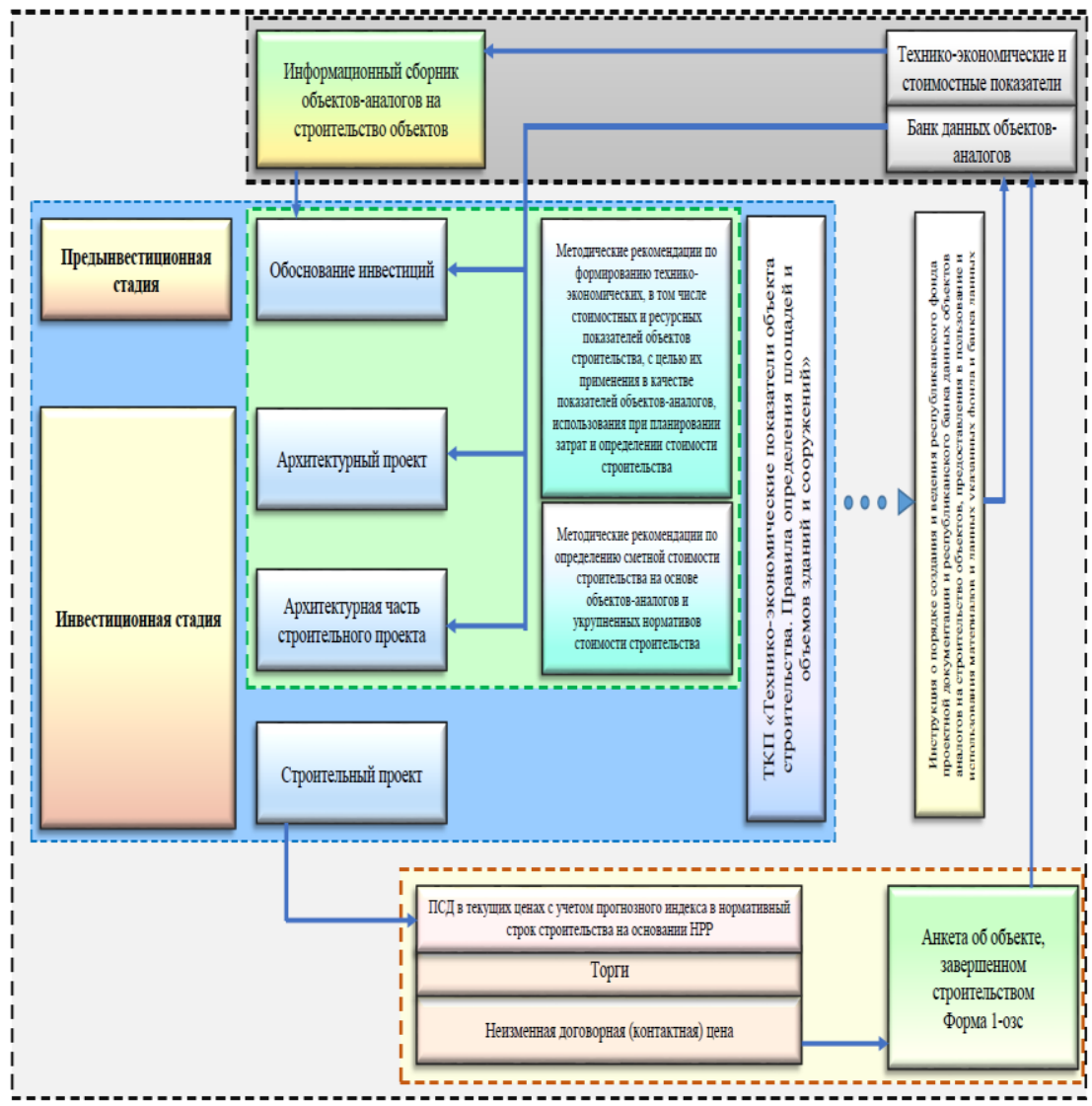

Рис. 1. Принципиальная схема формирования республиканского банка данных объектов-аналогов (Источник: собственная разработка)

Технико-экономические показатели республиканского банка данных объектованалогов формируются по структуре, учитывающей дифференциацию объектов по функциональному назначению.

В банке данных объектов-аналогов представлены объекты следующего функционального назначения [4]:

- объекты жилищного строительства (26 объектов);

- объектам социально-культурного назначения:

детские дошкольные учреждения (9 объектов);

школы (4 объекта); 
- объекты физкультурно-оздоровительного назначения (4 объекта);

- объекты здравоохранения, отдыха и туризма (3 объекта);

- объекты торговли (2 объекта);

- административные учреждения (10 объектов);

- объекты общественного питания (1 объект);

- объекты прочего назначения (2 объекта);

- объект транспортного строительства: стоянка для автомобильного транспорта (1 объект);

- объекты промышленного назначения (склад).

\section{РЕСПУБЛИКАНСКИЙ БАНК ДАННЫХ ОБЪЕКТОВ-АНАЛОГОВ}

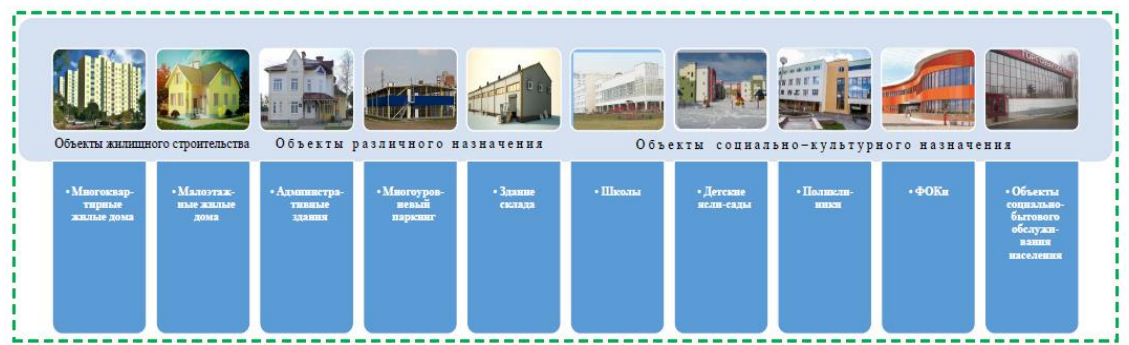

Находятся в банке данных объектов-аналогов

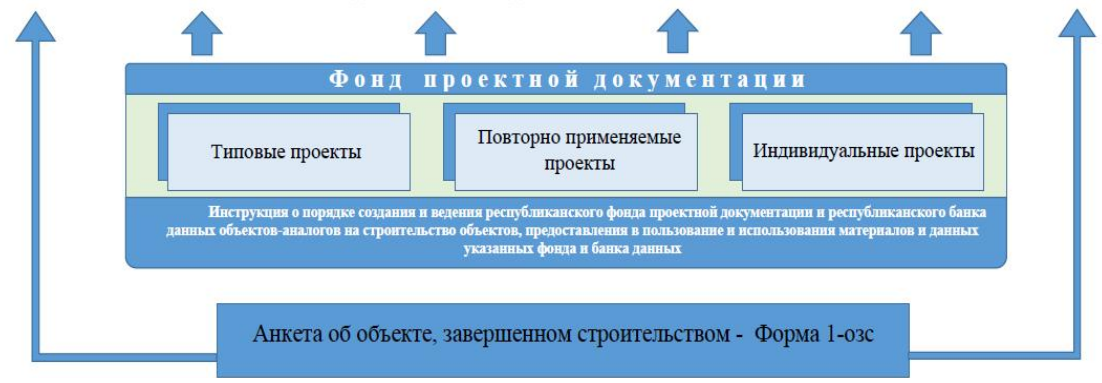

Рис. 2. Структура наполнения республиканского банка данных объектованалогов ( Источник: собственная разработка)

В период 2019-2020 года планируется включить в республиканский банк данных объектов-аналогов 15 новых объектов. Структура республиканского банка данных объектов-аналогов представлена на рис. 3.

Как отмечалось ранее, республиканский банк данных объектов-аналогов включает в себя технико-экономические показатели разной степени детализации, в том числе стоимостные и ресурсные показатели, по группам затрат в разрезе проектно-технологических модулей, характеризующих виды работ и затрат, возникающих при создании строительной продукции, отвечающие различным целям на всех этапах планирования затрат. 


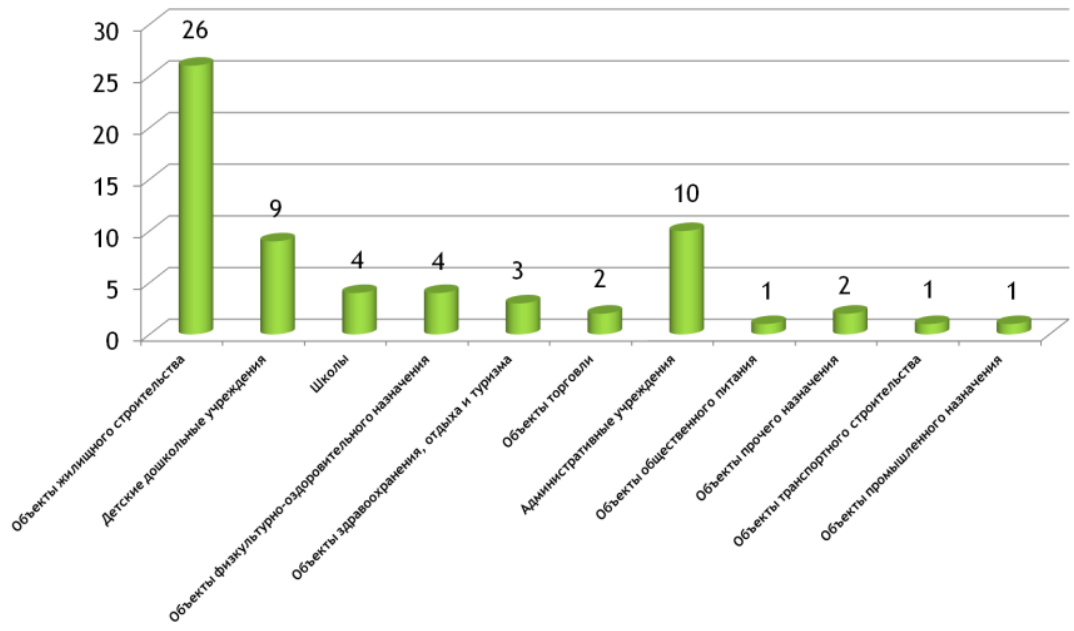

Рис. 3. Структура республиканского банка данных объектов-аналогов (Источник: собственная разработка)

Структура и взаимоувязка затрат представлена на рис. 4.

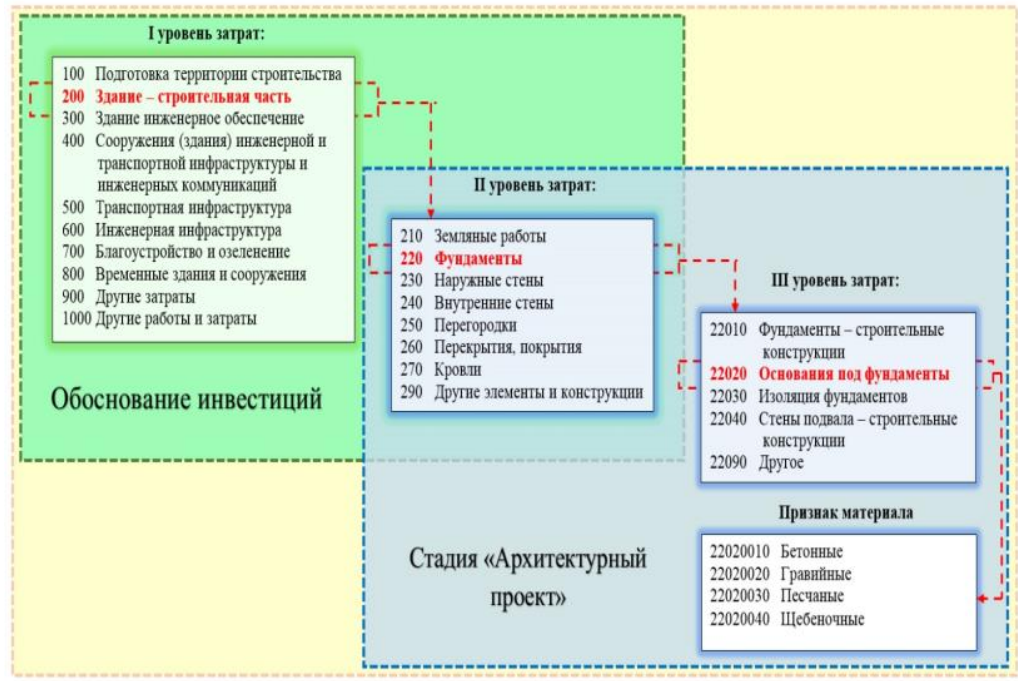

Рис. 4. Структура затрат в строительстве (Источник: собственная разработка) 
При определении объемов капитальных вложений в строительство и осуществлении финансово-экономических расчетов при разработке предпроектной документации используются показатели групп затрат І-го уровня республиканского банка данных объектов-аналогов на строительство объектов. Показатели групп затрат II-го уровня могут применяться на предпроектной стадии при оценке проектных решений по отдельным конструкциям или частям здания, сооружения. Определение стоимости строительства при разработке и реализации инвестиционного проекта на стадиях архитектурного и строительного проекта выполняется по группам затрат II-го и III-го уровня в разрезе ПТМ [5].

Затраты І-го и II-го уровня приводятся на расчетный показатель затрат по объекту, главный ценообразующий параметр - объем (брутто, нетто), общую площадь (брутто, нетто). Данные о показателях объемов (м3) и площадей (м2) принимаются на основании таблицы технико-экономических показателей проектной документации объекта-аналога, рассчитываемых в соответствии с требованиями нормативных технических актов по расчету площадей и объемов при проектировании объектов строительства.

Затраты III-го уровня зависят от главного ценообразующего фактора - вида конструкций или материала и определяются стоимостными и ресурсными показателями работ и затрат ПТМ и принимается в соответствии с конкретным проектом.

Связь в структуре затрат II-го и III-го уровней организуется по коду ПТМ, характеризующего укрупненный элемент здания (сооружения) или вида работ с дополнением на III-ем уровне признака, уточняющего его характеристику по виду основного материала, например: стены/стены из монолитного бетона.

Республиканский банк данных включает в себе информацию по следующим разделам:

- технико-экономические показатели, основные инженерно-технические решения;

- стоимостные показатели объекта строительства по группам затрат I-го уровня в текущих ценах, приведенные к ценам базисного периода на 1 января текущего года с учетом данных статистических наблюдений по объекту завершенному строительством в соответствии с формой 4-озс «Анкетой об объекте, завершенном строительством»;

- стоимостные показатели, сформированные по группам затрат II-го и III-го уровней, и включающие заработную плату рабочих, стоимость эксплуатации строительных машин и механизмов, в том числе заработную плату машинистов, стоимость строительных материалов и транспортных затрат, оборудования, стоимость общехозяйственных и общепроизводственных расходов; плановую прибыль;

- показатели расхода ресурсов в натуральном измерении, укрупненные в целом по зданию (сооружению), а также в разрезе ПТМ.

В республиканском банке данных объектов-аналогов дополнительно к стоимостным показателям групп затрат I-го и II-го уровня формируется информация о показателях в процентом выражении, характеризующих структуру 
по группам затрат, отражающую характер распределения (удельный вес) в общей стоимости затрат по объекту.

Стоимостные показатели республиканского банка данных объектов-аналогов устанавливаются на 1 января текущего года и действуют в течение года.

При использовании ресурсных показателей объекта-аналога стоимость строительства определяется в ценах периода, в котором выполняются расчеты с учетом нормативной продолжительности строительства и прогнозных показателей (индексов) цен в строительстве.

По объектам аналогам включенным в республиканский банк данных объектов-аналогов разработан «Информационный сборник объектов-аналогов на строительство объектов 2019 год», содержащий в себе следующую информацию по объектам-аналогам (рис. 5):

\begin{tabular}{|c|c|}
\hline №п/ח & Наименование информационного блока каталога \\
\hline 1 & Эскиз (3D модель) объекта строительства \\
\hline 2 & $\begin{array}{l}\text { Каталожные листы, содержащие информацию согласно } \\
\text { ТКП 45-1.02-157.2009 }\end{array}$ \\
\hline 3 & $\begin{array}{l}\text { Описание конструктивных элементов объекта и видов работ } \\
\text { А. Здание - строительная часть. } \\
\text { Б. Здание - инженерное обеспечение }\end{array}$ \\
\hline 4 & $\begin{array}{l}\text { Стоимостные показатели строительства объекта по объекту в ценах на } 1 \\
\text { января } 2015 \text { года, приведенные на: } \\
\text {-1 м2 общей площади, тыс руб.; } \\
\text {-1 м2 полезной площади, тыс руб.; } \\
\text {-1 м3 строительного объема, тыс руб; } \\
\text {-удельный показатель стоимости конструктивного элемента в целом по } \\
\text { объекту, \%. }\end{array}$ \\
\hline
\end{tabular}

Рис. 5. Информация, содержащаяся по объектам-аналогам, включенным в республиканский банк данных объектов-аналогов (Источник: собственная разработка)

Также для осуществления привязки стоимостных показателей объектованалогов к регионам строительства в технической части Информационного сборника объектов-аналогов на строительство объектов приведены поправочные коэффициенты.

Информационный сборник объектов-аналогов на строительство объектов предназначен для применения при определении сметной стоимости на строительство объектов на предынвестиционной стадии, которая включает разработку предпроектной документации, необходимой для архитектурной и инженерной подготовки к реализации инвестиционного проекта в строительстве, финансовую и экономическую оценку инвестиционного проекта, подготовку и выдачу комплекта разрешительной документации на строительство. В состав предпроектной документации могут включаться декларация о намерениях, 
обоснование инвестиций и план управления проектом, бизнес-план и задание на проектирование.

К концу года выйдет очередной сборник объектов-аналогов на строительство объектов социально-культурного назначения.

Для широкого внедрения методов вариантного проектирования в увязке с экономической частью проекта, разработанной на основании укрупненных показателей стоимости и технико-экономических показателей объектов-аналогов, повышение достоверности сметно-экономических вопросов, необходимо:

- постоянная актуализация и пополнение реальной информации республиканской информационной базы технико-экономических показателей построенных объектов, а также республиканского фонда проектной документации;

- внедрение современных программных комплексов, увязанных с уже существующими по автоматизированному проектированию и разработке сметной документации;

- совершенствование республиканской базы нормативов расхода ресурсов с учетом новой системы классификации и кодирования.

Экономический эффект от применения объектов-аналогов для определения стоимости строительства на прединвестиционной стадии достигается за счет снижения продолжительности формирования сметной документации, повышения достоверности расчетов сметной стоимости в текущих ценах при обосновании инвестиций и разработке архитектурного проекта, а также за счет создания информационной основы для внедрения вариантного проектирования.

Вариантный метод проектирования в настоящее время применяется все чаще: он позволяет заказчику увидеть все возможные способы строительства здания или сооружения, определить наиболее выгодные варианты экономии и способы уменьшения трудозатрат.

Состав базы объектов-аналогов соответствует основным направлениям развития строительного рынка, также особое внимание уделяется строительству, финансируемому за счет бюджетных средств.

Расширение базы объектов-аналогов осуществляется на основании всестороннего анализа поступлений в фонд проектной документации, а также тенденций в сфере строительства. Банк данных объектов-аналогов дает возможность быстрой и адекватной оценки необходимого объема инвестиций с проработкой нескольких альтернативных конструктивных и объемнопланировочных решений. В связи с тем, что государство осуществляет многовекторную политику - развитие строительства жилья, финансируемого с государственной поддержкой, а также большого количества направлений социальной сферы, актуализировать и пополнять базу объектов-аналогов необходимо с учетом интересов и потребностей заказчиков (застройщиков).

Схема использования объектов-аналогов для определения стоимости строительства проектируемого объекта представлена на рис. 6. 


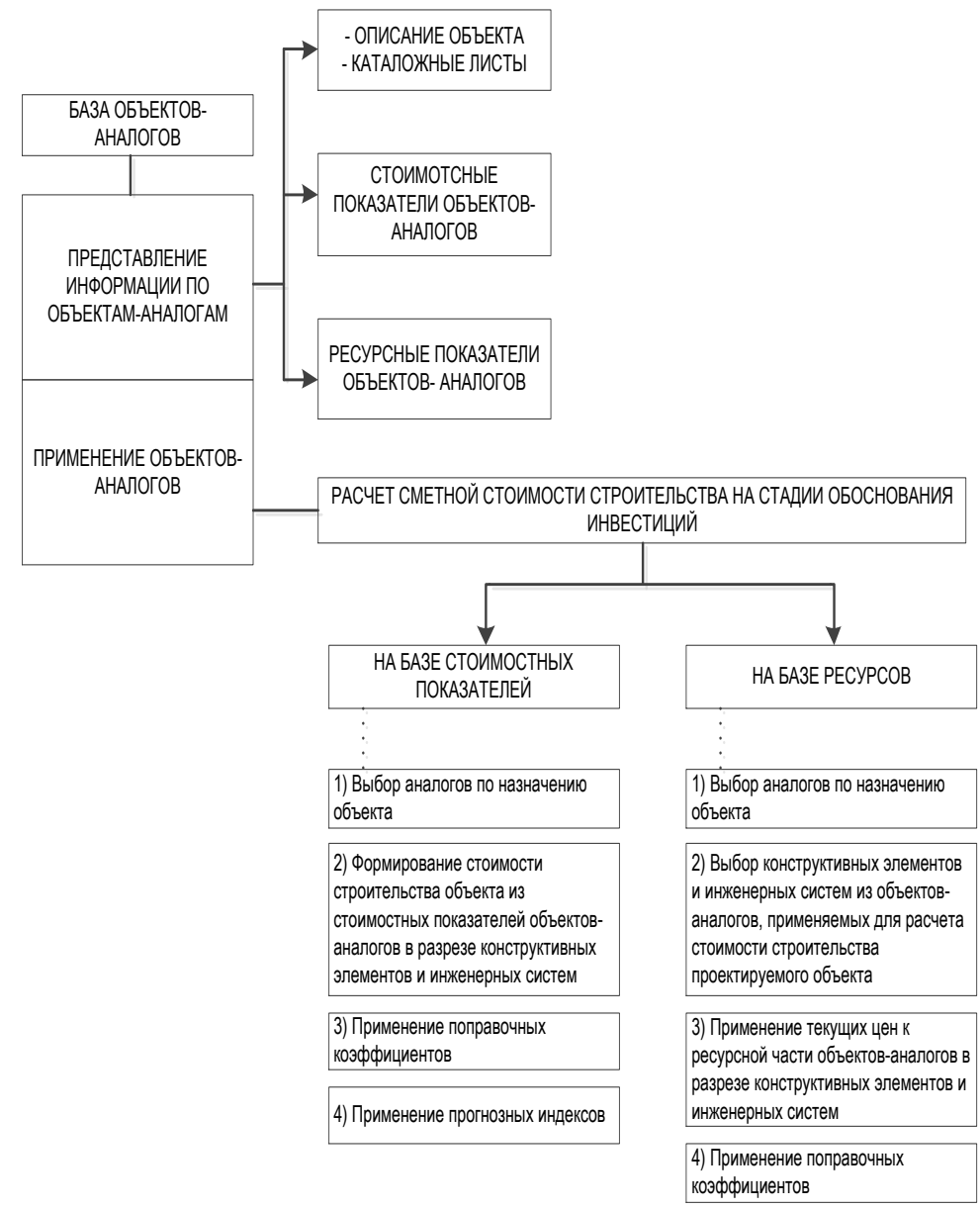

Рис. 6. Схема использования объектов-аналогов для определения стоимости строительства проектируемого объекта [4]

Таким образом, можно сделать вывод, что такой инструмент ценообразования, как объекты-аналоги, является перспективным и гарантирующим высокий экономический эффект на фоне государственной заинтересованности в привлечении инвестиций в строительный комплекс. Необходима дальнейшая разработка и включение технико-экономических и стоимостных показателей объектов-аналогов в банк данных, а также разработка автоматизированной системы, позволяющей вести расчеты стоимости строительства на основании информационной базы республиканского банка данных объектов-аналогов [4]. 
Задачами автоматизированной системы являются:

- организация механизма взаимодействия автоматизированной системы с республиканским банком данных объектов-аналогов;

- предоставление пользователям удобных визуальных форм для просмотра хранимых в базе данных объектов;

- создание в конструкторе новых пользовательских объектов на основе уже существующих в базе данных системы;

- разработка механизма включения информации по объектам-аналогам в автоматизированную систему;

- сбор и хранение статистической информации по действиям пользователей в системе;

- расчет стоимости строительства на основе стоимостных показателей объектов-аналогов с приведением расчета в текущий уровень цен при помощи прогнозного индекса и привязкой соответствующих ресурсов, необходимых для строительного производства.

Основной метод расчетов - это аналоговый метод сравнения с возможностью комбинирования групп затрат по конструктивным элементам и внутренним инженерным системам для поиска оптимального решения, отвечающего требованиям заказчика и нормативным документам.

Метод аналогового сравнения предполагает определение стоимости объекта на основе анализа цен аналогичных (но не идентичных) объектов и корректировки стоимости аналогов на отличия от объекта оценки по элементам сравнения (функциональные, параметрические и т.д.).

Выбор работы по стоимости, сформированной комбинированием групп затрат, или стоимости конкретного аналога зависит от полноты исходных данных и близости показателей проектируемого объекта к конкретному аналогу. В автоматизированную систему будет заложена возможность создания искусственного аналога набором данных из различных аналогов по отдельным группам затрат.

Работа по оценке затрат строится на анализе следующей информации:

- назначение проектируемого объекта;

- технические характеристики (количественные характеристики: мощность, вместимость, состав функциональных групп, площадь и т.д.);

- требования к строительным конструкциям (вид конструкций), требование к оборудованию), расположение объекта.

Важным этапом обработки данных является работа с поправками: на регион и зону строительства. Расчеты затрат с учетом поправок приближают условия строительства аналогов к условиям строительства проектируемого объекта при расчете по удельным показателям стоимости.

На первом этапе расчетов определяются общие затраты по объекту. Можно работать с конкретным аналогом или средней ценой, полученной в результате обработки ряда аналогов.

После выбора аналога выполняются расчеты стоимости исходя из структурированных затрат по аналогам на выбранную единицу измерения, например, 1 м2 полезной площади. 
Автоматизированная система позволит получить укрупненные показатели ресурсной части аналога, что в перспективе послужит основанием для выполнения расчетов через оценку расхода укрупненных ресурсов в натуральных единицах измерения. Для этого уже имеется нормативная база материалов, в которой материалы, близкие по техническим характеристикам и назначению объединены в укрупненные группы.

При включении в автоматизированную систему алгоритма перевода расходов ресурсов в различных единицах измерения к одной (общей) единице возможно создание блока данных, характеризующих удельные показатели материалоемкости по объектам различного назначения.

Предполагается, что стоимость строительства объекта будет формироваться поэтапно на различных стадиях инвестиционного процесса с учетом интересов, как заказчика, так и подрядчика. Также гарантируется точность конечного расчета, удовлетворяющая требованиям инвестора по стоимостному параметру с уровнем достоверности $\pm 10 \%$ (аналогично практике архитектурной и строительной деятельности в европейских странах).

В целях экономической оценки проектных решений необходимо, чтобы методы проектирования основывались на системном подходе выбора оптимальных вариантов с параллельным расчетом возможных затрат.

Выводы: Предлагаемая к разработке автоматизированная информационноаналитическая система позволит вести расчеты стоимости строительства на основании информационной базы республиканского банка данных объектов аналогов. Данный расчет охватывает все затраты, которые должен понести заказчик, чтобы получить объект, готовый к эксплуатации. Кроме того, уровень точности полученных данных позволит сориентировать заказчика касательно объема предполагаемых к освоению инвестиций в рамках планирования своей хозяйственной деятельности на долгосрочную перспективу.

\section{Список литературы:}

1. Развитие республиканского банка данных объектов-аналогов в рамках реализации концепции совершенствования системы ценообразования в строительстве Республики Беларусь: материалы III Международной научнопрактической конференции «Методология и принципы ценообразования в строительстве. Инновационные технологии в строительной отрасли и их внедрение», Минск, 1-2 декабря 2015 г. / производственно-практическое издание / РУП «Республиканский научно-технический центр по ценообразованию в строительстве»; редкол. Пурс Г. А. (отв. ред.) [и др.]. - Минск, 2015 - 125 с.

2 Пурс, Г. А. Результаты модернизации системы ценообразования в строительной отрасли республики Беларусь (2012-2018 г.г.) / Г. А. Пурс // Строительство и ценообразование: производственно-практический журнал. 2019. №5. C. 3-18.

3. Об утверждении Инструкции о порядке создания и ведения республиканского фонда проектной документации и республиканского банка данных объектов-аналогов на строительство объектов, предоставления в пользование и использования материалов и данных указанных фонда и банка 
данных [Электронный ресурс] : постановление Минстройархитектуры, 26 марта 2014 г., №14 // Национальный правовой Интернет-портал Республики Беларусь. Режим доступа: http://pravo.by/document/?guid=12551\&p0=W21428852\&p1=1. (21.05.2019)

4. Провести исследование, анализ и разработку информационной базы республиканского банка данных объектов-аналогов, технико-экономических, стоимостных и ресурсных показателей объектов строительства (5 объектов и актуализация 56) (промежуточный) / ГП «РНТЦ по ценообразованию в строительстве; рук. темы Михалькевич Н. М. - Минск, 2018, - 3061 с. - №ГР 20180429.

5. Исследование и разработка методических рекомендаций по формированию технико-экономических и стоимостных показателей объектов строительства с целью их применения в качестве показателей объектов-аналогов: отчет о НИР (заключ.) / ГП «РНТЦ по ценообразованию в строительстве; рук. темы Ковалева О.Н. - Минск, 2013. - 148 с.

6. Сосновская, У. В. Развитие и внедрение сравнительного подхода в систему ценообразования в строительстве / У. В. Сосновская // Экономика строительного комплекса и городского хозяйства: материалы Международной научнотехнической конференции (Минск, 8-15 декабря 2015 г.) / Белорусский национальный технический университет, Строительный факультет. - Минск : БНТУ, 2016.

\section{References:}

1. Purs, H. A. (2015). Razvytye respublykanskoho banka dannыkh obъektovanalohov $\mathrm{v}$ ramkakh realyzatsyy kontseptsyy sovershenstvovanyia systemы tsenoobrazovanyia v stroytelstve Respublyky Belarus: materyaly III Mezhdunarodnoi nauchno- praktycheskoi konferentsyy «Metodolohyia y pryntsypы tsenoobrazovanyia v stroytelstve. Ynnovatsyonnыe tekhnolohyy v stroytelnoi otrasly y ykh vnedrenye», /proyzvodstvenno-praktycheskoe yzdanye RUP «Respublykanskyi nauchnotekhnycheskyi tsentr po tsenoobrazovanyiu v stroytelstve»; redkol. (otv. red.) [y dr.]. Minsk, $125 \mathrm{~s}$.

2. Purs, H.A. (2019). Rezultatы modernyzatsyy systemы tsenoobrazovanyia v stroytelnoi otrasly. Stroytelstvo y tsenoobrazovanye: proyzvodstvenno-praktycheskyi zhurnal, 5, 3-18.

3. Ob utverzhdenyy Instruktsyy o poriadke sozdanyia y vedenyia respublykanskoho fonda proektnoi dokumentatsyy y respublykanskoho banka dannыkh obъektovanalohov na stroytelstvo obъektov, predostavlenyia $\mathrm{v}$ polzovanye y yspolzovanyia materyalov y dannykh ukazannykh fonda y banka dannykh [Elektronnyi resurs]: postanovlenye Mynstroiarkhytektury, 26 marta 2014 h., №14 // Natsyonalnyi pravovoi Internet-portal Respublyky Belarus. $\quad$ URL: http://pravo.by/document/?guid=12551\&p0=W21428852\&p1=1. (21.05.2019)

4. Mykhalkevych, N.M. (2018). Provesty yssledovanye, analyz y razrabotku ynformatsyonnoi bazы respublykanskoho banka dannыkh obъektov-analohov, tekhnyko-эkonomycheskykh, stoymostnыkh y resursnykh pokazatelei obъektov stroytelstva (5 obъektov y aktualyzatsyia 56) (promezhutochnыi) /HP «RNTTs po tsenoobrazovanyiu v stroytelstve; 3061 s. - №HR 20180429. 
5. Kovaleva, O.N. (2013). Yssledovanye y razrabotka metodycheskykh rekomendatsyi po formyrovanyiu tekhnyko-эkonomycheskykh y stoymostnыkh pokazatelei obъektov stroytelstva $\mathrm{s}$ tseliu ykh prymenenyia $\mathrm{v}$ kachestve pokazatelei obъektov-analohov: otchet o NYR (zakliuch.) / HP «RNTTs po tsenoobrazovanyiu v stroytelstve; ruk. temы $148 \mathrm{~s}$.

6. Sosnovskaia, U.V. (2016). Razvytye y vnedrenye sravnytelnoho podkhoda v systemu tsenoobrazovanyia $\mathrm{v}$ stroytelstve. Ekonomyka stroytelnoho kompleksa y horodskoho khoziaistva: materyalы Mezhdunarodnoi nauchno- tekhnycheskoi konferentsyy.

\section{Г.А. Пурс, Н.М. Міхалькевич}

Розробка методологічних $і$ організаційних підходом щодо визначення вартості будівництва за допомогою використання варіантного проектування

Найважливішим кроком в реалізачї ступеневої модернізаџї системи ціноутворення в будівельному комплексі стала розробка методологічних та організаиійних підходів щодо визначення вартості будівнищтва за допомогою використання варіантного проектування, которій дозволяє замовнику побачити всі можливі способи будівництва будівлі або споруди, визначити найбільш вигідні варіанти економії і способи зменшення трудовитрат.

Стаття присвячена вивченню причин необхідності вдосконалення системи ціноутворення будівельної галузі та впровадження аналогового методу визначення вартості будівництва на стадії обгрунтування інвестицій і розробки архітектурного проекту, дослідження бази нормативно-правових документів, спрямованої на реалізацію аналогового методу формування кошторисної вартості будівнищтва. Також в статті розглянуті перспективні напрямки застосування об'єктів-аналогів і напрямки подальшого розвитку об'єктів-аналогів в якості інструменту для розрахунку вартості будівництва на базі технологіі інформачійного моделювання будівель.

Економічний ефект від застосування об'єктів-аналогів для визначення вартості будівничтва на передінвестииійній стадії досягається за рахунок зниження тривалості формування кошторисної документації, підвищення достовірності розрахунків кошторисної вартості в поточних цінах при обгрунтуванні інвестицій та розробиі архітектурного проекту, а також за рахунок створення інформаційної основи для впровадження варіантного проектування . Банк даних об'єктів-аналогів дає можливість швидкої та адекватної оцінки необхідного обсягу інвестицій з опраџюванням кількох альтернативних конструктивних і об'ємно-планувальних рішень.

Пропонована до розробки автоматизована інформачійно-аналітична система дозволить вести розрахунки вартості будівництва на підставі інформачійноі бази республіканського банку даних об'єктів аналогів. Даний розрахунок охоплює всі витрати, які повинен понести замовник, щоб отримати об'єкт, готовий до експлуатаиії. Крім того, рівень точності отриманих даних дозволить зорієнтувати замовника щодо обсягу передбачуваних до освоєння інвестииій в рамках планування своєї господарської діяльності на довгострокову перспективу.

Ключові слова: вартість будівництва, кочторисна вартість, варіантне проектування, Білорусь. 


\section{G.A. Purs, N.M. Mikhalkevich}

Development of methodological and organizational approach to determine the cost of construction through the use of variant design

The most important step in the implementation of the multi-stage modernization of the pricing system in the construction complex was the development of methodological and organizational approaches to determining the cost of construction through the use of variant design, which allows the customer to see all possible ways of building a building or structure, to determine the most cost-effective options and ways to reduce labor.

The article is devoted to the study of the reasons for the need to improve the pricing system of the construction industry and the introduction of an analogous method of determining the cost of construction at the stage of investment substantiation and development of an architectural project, to study the base of regulatory documents aimed at the implementation of the analogous method of forming the estimated cost of construction. The article also discusses perspective directions for the use of analog objects and directions for the further development of analog objects as a tool for calculating the cost of construction based on information modeling of buildings.

The economic effect of the use of analogues to determine the cost of construction at the pre-investment stage is achieved by reducing the duration of the formation of estimated documentation, increasing the reliability of calculations of estimated value at current prices when substantiating investments and developing an architectural project, as well as by creating an information basis for the implementation of variant design . The Data Bank of Analog Objects provides an opportunity to quickly and adequately evaluate the required volume of investments with the development of several alternative design and volume planning solutions.

The automated information-analytical system proposed for development will allow to calculate the cost of construction on the basis of the information base of the republican bank of data of objects of analogues. This calculation covers all costs that the customer must incur in order to get the facility ready for operation. In addition, the level of accuracy of the obtained data will allow you to orient the customer with regard to the volume of investments expected to be used in the planning of their business activities for the long term.

Keywords: construction cost, estimated cost, variant design, Belarus.

\section{Посилання на статтю:}

APA: Purs, H.A. \& Mykalkevych, N.M. (2019). Razrabotka metodolohycheskykh y orhanyzatsyonnыkh podkhodom po opredelenyiu stoymosty stroytelstva posredstvom yspolzovanyia varyantnoho proektyrovanyia. Shliakhy pidvyshchennia efektyvnosti budivnytstva $v$ umovakh formuvannia rynkovykh vidnosyn, 42, 153 -169.

ДСТУ: Пурс Г.А. Разработка методологических и организационных подходом по определению стоимости строительства посредством использования вариантного проектирования [Текст] / Г.А. Пурс, Н.М. Михалькевич // Шляхи підвищення ефективності будівництва в умовах формування ринкових відносин. -2019 . - № 42. - С. $153-169$. 